\title{
Uma análise de consumo de alimentos probióticos com estudantes de uma instituição
}

\section{de ensino superior}

\author{
Probiotic products consuming analysis with a university education institution students \\ Análisis del consumo de alimentos probioticos con estudiantes de una institución de educación
}

superior

Recebido: 02/06/2021 | Revisado: 13/06/2021 | Aceito: 15/06/2021 | Publicado: 30/06/2021

Vinícius Costa Barros

ORCID: https://orcid.org/0000-0002-3339-5040 Universidade Federal do Maranhão, Brasil

E-mail: vi_costa_b@outlook.com

Adriana Crispim de Freitas

ORCID: https://orcid.org/0000-0001-6310-0015 Universidade Federal do Maranhão, Brasil

E-mail: adriana.crispim@ufma.br

Virlane Kelly Lima Hunaldo

ORCID: https://orcid.org/0000-0002-5827-2987 Universidade Federal do Maranhão, Brasil

E-mail: virlanekelly@yahoo.com.br

Iago Hudson da Silva Sousa

ORCID: https://orcid.org/0000-0002-3415-8012 Universidade Federal do Maranhão, Brasil

E-mail: iago_hudson@hotmail.com

\begin{abstract}
Resumo
Cuidados com a saúde e atenção aos hábitos de vida vêm ganhando atenção nesses últimos anos e a mudança nos hábitos alimentares apresenta-se em relevância, uma vez que à inserção de alguns alimentos podem ajudar na manutenção da saúde. Dentre esses alimentos estão em destaque os probióticos, que através da ação microbiana ajudam em atividades benéficas do sistema digestivo e imunológico. O objetivo desse trabalho foi investigar o conhecimento e comportamento de consumo de alimentos probióticos por estudantes de uma instituição de ensino superior e verificar o julgamento de uma proposta de intenção de compra de Kefir a base de albedo de maracujá. Os participantes da pesquisa foram 327 estudantes de uma Instituição de Ensino Superior que responderam um questionário online, divulgado nos grupos de WhatsApp e e-mails institucionais. As respostas obtidas foram tabuladas e analisadas de forma qualitativa e quantitativa. A maioria dos participantes da pesquisa $(72,8 \%)$ estavam na faixa etária de 18 a 24 anos, onde $32,1 \%$ possuem renda entre $\mathrm{R} \$ 1.100,00$ e $\mathrm{R} \$ 2.200,00$, os participantes apresentam rotina sedentária, porém sem problemas de saúde. Parte dos estudantes definiram corretamente "alimentos probióticos", possuindo hábitos de consumo semestral tendo como principal alimento de inserção e frequência o leite fermentado, e de maior preferência o iogurte. Os participantes não conhecem e nem consomem o produto Kefir, com preferência por alimentos funcionais a base de leite, levemente ácidos e estão abertos à proposta de compra de um Kefir a base de albedo do maracujá, sendo necessário o desenvolvimento do produto e testes sensoriais.
\end{abstract}

Palavras-chave: Kefir; Perfil de consumidor; Alimentos funcionais.

\begin{abstract}
Health care and attention to lifestyle habits have been gaining attention in recent years and the change in eating habits is relevant since the inclusion of some foods can help maintain health. Among these foods, probiotics are highlighted, which through microbial action help in beneficial activities of the digestive and immune systems. The objective of this work was to investigate the knowledge and behavior of consumption of probiotic foods by students from a higher education institution and to verify the judgment of a proposed purchase intention of kefir based on passion fruit albedo. The research participants were 327 students from a Higher Education Institution who answered an online questionnaire, published in WhatsApp groups and institutional emails. The responses obtained were tabulated and analyzed qualitatively and quantitatively. Most research participants (72.8\%) were aged between 18 and 24 years old, where $32.1 \%$ have an income between $\mathrm{R} \$ 1100.00$ and $\mathrm{R} \$ 2200.00$, the participants have a sedentary routine, but without health problems. Part of the students correctly defined "probiotic foods", having habits of consumption every six months, with fermented milk as the main insertion and frequency food, and more preferably yogurt. Participants do not
\end{abstract}


know or consume the Kefir product, preferring functional foods based on milk, slightly acidic and are open to the proposal to purchase a Kefir based on passion fruit albedo, requiring product development and sensory tests.

Keywords: Kefir; Consumer profile; Functional foods.

\section{Resumen}

El cuidado de la salud y la atención a los hábitos de vida han ido ganando atención en los últimos años y el cambio en los hábitos alimentarios es relevante, ya que la inclusión de algunos alimentos puede ayudar a mantener la salud. Entre estos alimentos se destacan los probióticos, que por su acción microbiana ayudan en actividades beneficiosas del sistema digestivo e inmunológico. El objetivo de este trabajo fue investigar el conocimiento y comportamiento del consumo de alimentos probióticos por estudiantes de una institución de educación superior y verificar el juicio de una intención de compra propuesta de kéfir basada en el albedo de la maracuyá. Los participantes de la investigación fueron 327 estudiantes de una Institución de Educación Superior que respondieron un cuestionario en línea, publicado en grupos de WhatsApp y correos electrónicos institucionales. Las respuestas obtenidas fueron tabuladas y analizadas cualitativa y cuantitativamente. La mayoría de los participantes de la investigación (72,8\%) tenían entre 18 y 24 años, donde el $32,1 \%$ tiene un ingreso entre $\mathrm{R} \$ 1.100,00$ y $\mathrm{R} \$ 2.200,00$, los participantes tienen una rutina sedentaria, pero sin problemas de salud. Parte de los estudiantes definieron correctamente los "alimentos probióticos", teniendo hábitos de consumo semestrales, siendo la leche fermentada el principal alimento de inserción y frecuencia, y más preferentemente el yogur. Los participantes no conocen ni consumen el producto de kéfir, prefieren alimentos funcionales a base de leche, ligeramente ácidos y están abiertos a la propuesta de comprar un kéfir a base de albedo de maracuyá, lo que requiere el desarrollo del producto y pruebas sensoriales.

Palabras clave: Kéfir; Perfil de consumidor; Alimentos funcionales.

\section{Introdução}

Os alimentos funcionais são considerados uma nova tendência do mercado alimentício (Kleerebezem et. al., 2019) desde a última década por razões relacionadas ao crescente mercado dentro do setor de alimentos como seguimento de dietas, regulamentação de produtos alimentícios funcionais pelas agências responsáveis reconhecendo seus benefícios à saúde e incentivo do Estado na promoção à saúde e atenção básica à saúde (Zhou 2020; Kim et. al., 2020). Os alimentos funcionais representam um nicho de mercado extremamente rentável, pois são produtos com alto valor agregado e com um marketing agressivo na busca pelo consumo. As indústrias alimentícias investem em pesquisadores e tecnologias visando os efeitos metabólicos, fisiológicos e benéficos à saúde (Silva, Orlandelli, 2019). Dentre os principais alimentos funcionais disponíveis destacam-se os vegetais, peixes, azeites, cereais, chás, produtos lácteos e enriquecidos com probióticos e prebióticos que visam estimular as funções múltiplas fisiológicas alegadas (Furtado, 2017; Balthazar et al., 2017; Yahfoufi et al., 2018).

A indústria de alimentos vem introduzindo uma diversidade de produtos probióticos, buscando atender as expectativas do consumidor, quanto aos requisitos de manutenção da saúde e baixo custo, introduzindo no mercado alimentos com microrganismos benéficos a saúde e classificados como probióticos (Gallina et al., 2015; Artilha et al., 2020). A expansão no mercado de probióticos vem sendo presenciado desde 2016, com um aumento de 30\%, isso equivale a 32,2 bilhões de dólares para o ano de 2017, em 2022 espera-se que o mercado para probióticos cresça em até $7 \%$ globalmente, isso representa 64 bilhões de dólares na sua taxa de crescimento anual composta. Os lácteos são os probióticos mais consumidos no Brasil e a inovação em que a indústria de laticínios se encontra permite uma diversidade de produtos disponíveis para a escolha do consumidor, visto na previsão de crescimento de $11 \%$ no mercado desses produtos, sendo o maior e o que cresce mais rápido (Filbido et al., 2019).

Um dos probióticos que seguem a linha láctea, é o Kefir de leite (Jeong et al., 2017), um subproduto do leite resultante do processo fermentativo láctica e alcoólica. Já o kefir de água é cultivado em água contendo açúcar ou sucos de frutas. Os grãos são amarelos claros quando cultivados em leite e são ocres e pardos quando cultivados em açúcar mascavo (Otles \& Cagindi, 2003; Witthunhn et al., 2004; Weschenfelder, 2011). Apesar da sua trajetória milenar no Brasil, a cultura chegou há pouco tempo e de forma caseira, porém atrai cada vez mais consumidores (Manarini, 2018). 
O presente estudo teve o intuito de investigar o conhecimento e comportamento de consumo de alimentos probióticos por estudantes de uma instituição de ensino superior e verificar o julgamento de uma proposta de intenção de compra de Kefir a base de albedo de maracujá.

\section{Metodologia}

Este estudo se enquadra como transversal de caráter quantitativo e qualitativo (Vieira, Hossne, 2015) e correlacional (Bloch, Coutinho, 2009), cuja amostra foi composta por estudantes universitários selecionados aleatoriamente. A amostra do estudo foi composta de 327 acadêmicos, considerando uma população de 2193 discentes ativos, dos nove cursos de graduação e quatro cursos de pós-graduação, pertencentes a uma instituição de ensino superior do estado do Maranhão. Este estudo foi aprovado pelo Comitê de Ética da Universidade Federal do Maranhão (número de registro: 3.995.451).

O tamanho do espaço amostral com os parâmetros descritos calculado por:

$$
A=\frac{\frac{\left[z^{2} * p(1-p)\right]}{e^{2}}}{\frac{1+\left[z^{2} * p(1-p)\right]}{e^{2} * N}}
$$

$\mathrm{Z}$ = escore $\mathrm{Z}$ (tabelado), $\mathrm{p}$ = desvio padrão, $\mathrm{e}=$ margem de erro, $\mathrm{N}$ = tamanho da população

Os dados da pesquisa foram obtidos por meio do levantamento das características sociodemográficas, do perfil alimentar em relação a alimentos funcionais e da proposição de intenção de consumo e compra de um novo produto probiótico com discentes selecionados aleatoriamente, para tanto empregou um questionário investigativo utilizando a plataforma Google Forms. Esse instrumento de pesquisa foi previamente aplicado com 10 alunos do grupo de pesquisa, no qual sofreu ajustes e em seguida foi divulgado em ambiente virtual de grupos específicos dos discentes durante os meses de fevereiro e março de 2021.

O questionário realizado era composto por três seções, a primeira seção continha o termo de aceite dos participantes; a segunda seção continha 6 questões objetivas sobre o perfil social, englobando gênero, rotina, curso, idade e renda, as faixas de renda foram estabelecidas de acordo estudos em construtos demográficos realizados pelos Institutos Nacionais de Pesquisa; a terceira secção era composta por 2 perguntas discursivas e 12 objetivas relativas ao consumo de alimentos probióticos.

Após a coleta, respostas incompletas ou que não atenderam aos pré-requisitos da pesquisa foram descartadas, no total, foram coletadas 329 respostas, 2 respostas foram descartadas finalizando a população amostral de 327 participantes da pesquisa, valor obtido da equação para determinação de espaço amostral, encerrando assim o recebimento de respostas.

Os dados foram tabulados em planilhas do Excel® 2016/365 e do BioEstat ${ }^{\circledR}$ 5.0, agrupados e dispostos utilizando estatística simples descritiva organizando as informações como variáveis categóricas, sendo referenciadas por indicação numérica próprias para cada teste quantitativo.

Foram analisadas quantitativamente frequências absolutas e relativas, média e desvio padrão, teste de significância t de Student e teste Z, teste de significância e associação de variáveis de Qui-Quadrado, teste de aderência de Lilliefors, nas análises estatísticas o erro amostral foi de 5\% e um intervalo de confiança de 95\% de acordo com Bornia et. al. (2009). Os resultados qualitativos foram agrupados por categorias de acordo com Bardin (2011), as categorias foram estabelecidas pelos próprios autores após revisão literária, após o agrupamento foi observado em qual categoria há um comportamento mais expressivo da população amostral. 


\section{Resultados e Discussão}

\section{Perfil dos pesquisados}

Os resultados mostram que dentre os membros julgados $47,4 \%$ eram homens e $52,6 \%$ mulheres. Valores que se assemelham aos dados do IBGE (2019) com 48,2\% e 51,8\% para homens e mulheres, respectivamente.

A população analisada está no intervalo de 18-25 anos (73\%) e 26-35 anos (23\%), sendo 85,5\% estudantes de graduação e 14,5\% estudantes de pós-graduação.

O Gráfico 1 apresenta os resultados da análise da renda, faixa etária com o estilo de vida em relação a prática de exercícios dos participantes.

Gráfico 1: Frequência para renda, faixa etária e estilo de vida de estudantes de uma instituição do ensino superior do estado do Maranhão, 2021.

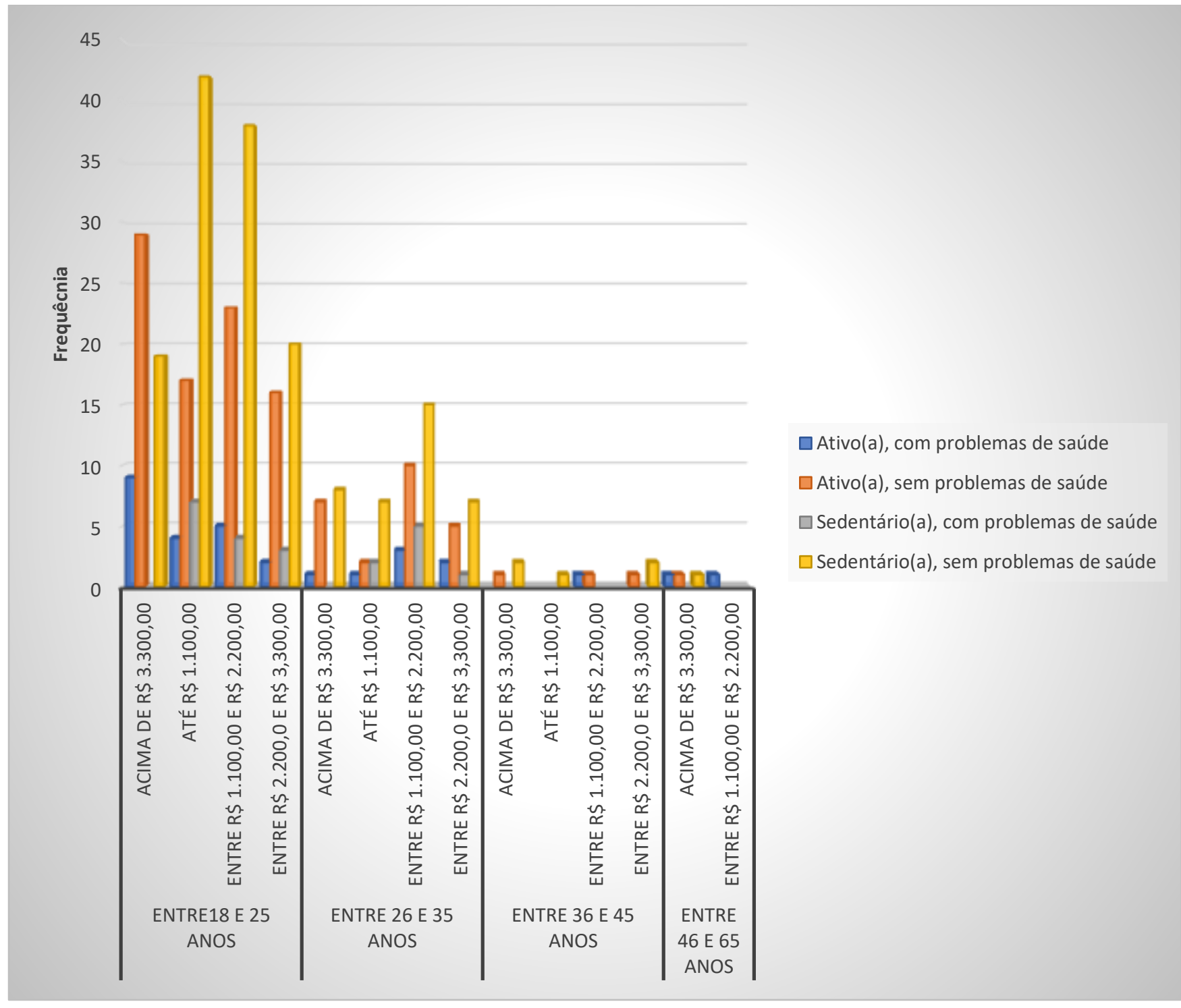

Fonte: Autores (2021).

A partir do Gráfico 1 pode ser observado que em quase todas as faixas etárias e classe social, os membros julgados podem ser classificados como sedentários, porém não apresentam problemas de saúde em sua rotina. Esse tipo de conforto 
descrito como "enquanto tudo está bem e a saúde não está em condições ruins", não é necessária a realização de atividades físicas e da inserção de alimentos que favoreçam a promoção da saúde.

O estilo de vida da população por ser estudantes de Ensino Superior, gastam muito tempo estudando e trabalhando, isso exclui as atividades físicas na rotina, de acordo com Silva e Costa (2014), há várias circunstâncias que levam o comportamento sedentário, como a falta de ambiente que estimulem a prática de exercícios físicos, influência de círculos de relacionamento, baixa estrutura de oportunidades ligadas a prática de exercícios, obstáculos físicos, falta de motivação e tempo. Das circunstâncias apresentadas por Silva e Costa, nesse estudo prevalece a baixa estrutura de oportunidades além da falta de tempo.

Ao fazer análise das respostas dos julgadores e da disposição delas no gráfico 1 infere-se que na faixa etária de 18-25 anos as mulheres são mais ativas que as demais faixas etárias e quando associada à renda de até $R$ \$1100,00 é o único perfil que ultrapassam os homens em rotina de exercícios e saúde. Em contrapartida, nessa mesma faixa etária, quanto maior a renda mais os homens se tornam ativos e as mulheres apresentam mais problemas de saúde. Na faixa etária de 26-35 anos as mulheres são responsáveis por contribuir no aumento do índice de sedentarismo e apresentam mais problemas de saúde que os homens, assim como na faixa de 46-65 anos, porém nessa faixa, 46-65 anos, os homens apresentam mais problemas de saúde que a população feminina. Na faixa de 36-45 não existe diferença significativa, a 5\% de significância, entre homens e mulheres em relação a serem ativos ou sedentários, de modo geral há um decréscimo de frequência de participantes nas variáveis de acordo com um aumento na faixa etária.

A população analisada por Filho (2020), foram predominantemente mulheres, representando $74,6 \%$ do total com idade entre 20 a 35 anos, renda mensal de até dois salários mínimos, praticam atividade física com pouca frequência e apresentam algum tipo de doença crônica, surpreendentemente $80,1 \%$ dos participantes, com destaque para a hipertensão, obesidade e diabetes, a população do estudo de Filho tem uma participação feminina, faixa de idade e renda maior que a população desse estudo, o que pode ser as variáveis para os problemas de saúde serem diferentes, sendo maiores também na pesquisa de Filho. Diferentemente da população de Cruz (2016), que se identificavam como 124 consumidores de alimentos funcionais, composto por $58,9 \%$ de mulheres e $51,1 \%$ de homens, de faixa etária de 25 a 30 anos em que majoritariamente tinham o médio completo ou superior incompleto, se assemelha mais com esse estudo, porém o estilo de vida não é analisado, apenas se os participantes são preocupados com seu estilo de vida ou não, e os participantes sendo preocupados com a saúde em grande parte de faixas de renda e idade revelam interesse no consumo de alimentos funcionais englobando os probióticos.

Mais da metade $(67,2 \%)$ da amostra analisada pertencem à área da saúde e tecnologia (Engenharia de Alimentos, Medicina, Enfermagem e Ciências Naturais), e os demais 32,7\% pertencem a áreas sociais (Direito, Pedagogia, Comunicação Social, Ciências Humanas, Ciências Contábeis), a descrição de um perfil de comportamento de consumo específico para estudantes de Instituições de Ensino Superior são raras, as demais pesquisas englobam uma amostra bem diversa, ou com público específico diferente, demostrando o diferencial desse construto. Holanda (2008), teve em seu construto uma amostra constituída por 198 estudantes de um ensino superior, a população tinha em média 25,4 anos, sendo metade da população feminina e metade masculina, sua população era constituída por universitários de nutrição e engenharia de produção, se assemelhando a essa pesquisa, tendo diferença da não participação das áreas de ciências sociais. Ao analisar os dados obtidos, o perfil social da amostra analisada nesse trabalho são estudantes homens ou mulheres majoritariamente de graduação e pós-graduação na área de ciências sociais, saúde e tecnologia com idade em torno de 24 anos pertencentes a classe média de baixa renda familiar (R\$ 1100,00 a R \$2200,00), com hábitos sedentários e sem problemas de saúde, diferentemente dos construtos dos demais autores onde em cada um dos perfis falta alguma variável atribuída a características dos participantes desse estudo. 


\section{Associação Renda e Rotina}

O caráter dessa pesquisa sai de transversal para correlacional quando há a associação das variáveis dispostas no estudo, as variáveis não associadas continuam com o caráter transversal. Entre os dados das variáveis renda e rotina que compuseram o Gráfico 1, resultou-se que a maior associação encontrada com $16,20 \%$ da mostra, é a renda de $R \$ 1100,00$ até $R \$ 2200,00$ com a rotina sedentária sem apresentar problemas de saúde, seguida pela associação da renda de até 1100,00 reais e a população sedentária que não apresenta problemas de saúde com 14,37\% da amostra.

Os que mais apresentaram problemas de saúde e levam um estilo de vida sedentária com 3,3\% da população tem renda de até $\mathrm{R} \$ 1100,00$ e 2,7\% têm renda de $\mathrm{R} \$ 1100,00$ a $\mathrm{R} \$ 2200,00$ reais. Ao realizar essa associação, tem-se que 8,8\% da população total corresponde a faixa de rotina ativa, que fazem exercício físicos, porém tem problemas de saúde e ao associar com a renda ,7,3\% da população tem renda de acima de $\mathrm{R} \$ 3300,00$ e essa é a maior associação para esse estilo de vida, percebese que realmente é um percentual pequeno ao comparar com os demais construtos de análise de perfil de consumo.

As pessoas mais ativas e sem problemas de saúde representado por 10,7\% da população tem renda entre RS 1.100,00 e R \$2.200,00 e essa é a maior associação para esse estilo de vida. Em geral, a associação descreve que as classes de menor poder aquisitivo são mais sedentárias não tendo problemas de saúde e uma pequena parte apresenta problemas de saúde, as pessoas mais ativas com problemas de saúde tem poder aquisitivo maior, e as mais ativas com nenhum problema corresponde a faixa média de poder aquisitivo

A associação entre essas variáveis é significativa, ao realizar o teste qui-quadrado para essa associação, os valores para o teste são 16,76 com um grau de liberdade 6, qui-quadrado tabelado tem valor de 12,59, isso dá um valor-p de 0,0102, como o erro amostral padrão para o estudo é 0,05 , percebe-se que a associação feita para as análises é efetiva.

\section{Associação gênero e rotina}

A partir da análise da Tabela 1, em geral, 55,66\% da população total analisada é sedentária e dessa população 59,89\% da população sedentária é composta pela população feminina. Os homens aparecem como as pessoas de rotina mais ativa devido uma diferença de 11,73\% nesse estilo de vida. A associação das duas variáveis se dá significativo, devido ao p-valor de 0.0006 ser menor que o erro amostral de 0,05 pelo teste de Qui-Quadrado disposto na Tabela 2. As mulheres tendem a se apresentar mais propensas ao sedentarismo do que os homens, mas não significa que a população masculina é integralmente saudável, o perfil geral do estudo ainda se identifica como jovens homens ou mulheres, sedentários, mas que não apresentam problemas de saúde.

Tabela 1: Associação gênero e rotina de estudantes de uma instituição do ensino superior do estado do Maranhão, 2021

\begin{tabular}{|l|l|l|r|r|r|}
\hline & $\begin{array}{l}\text { Ativo(a), } \\
\text { com } \\
\text { problemas } \\
\text { de saúde }\end{array}$ & $\begin{array}{l}\text { Ativo(a), } \\
\text { sem } \\
\text { problemas } \\
\text { de saúde }\end{array}$ & $\begin{array}{l}\text { Sedentário(a), } \\
\text { com problemas } \\
\text { de saúde }\end{array}$ & $\begin{array}{l}\text { Sedentário(a), } \\
\text { sem problemas } \\
\text { de saúde }\end{array}$ & $\begin{array}{l}\text { Total } \\
\text { Geral }\end{array}$ \\
\hline Feminino & 19 & 42 & 15 & 96 & 172 \\
\hline Masculino & 11 & 71 & 7 & 66 & 155 \\
\hline Total Geral & $\mathbf{3 0}$ & $\mathbf{1 1 3}$ & $\mathbf{2 2}$ & $\mathbf{1 6 2}$ & $\mathbf{3 2 7}$ \\
\hline
\end{tabular}

Fonte: Autores. 
Tabela 2: Teste Qui-Quadrado para a associação Gênero e Rotina.

\begin{tabular}{|l|l|}
\hline Tabela de Contingência & $\mathbf{2 X 4}$ \\
\hline Qui-Quadrado & 17.203 \\
\hline Grau de Liberdade & 3 \\
\hline p-valor & 0,00006 \\
\hline
\end{tabular}

Fonte: Autores.

\section{Conhecimento e consumo de Probióticos}

Os julgadores foram perguntados “Como você define um produto probiótico?", as respostas obtidas de forma qualitativa foram tabuladas e agrupadas em três segmentos: Que levam microrganismos benéficos na composição; saudável e benéfico; e não sei.

O primeiro segmento, que levam microrganismos benéficos na composição, dialoga com a legislação brasileira (Brasil, 2018), a Resolução da Diretoria Colegiada RDC No 241, definindo probióticos como "Produtos com microrganismos vivos que quando administrados em quantidades adequadas conferem um benefício à saúde do indivíduo". Este segmento tem como elemento substancial a compreensão de como a maioria dos participantes definem os alimentos probióticos, e os participantes majoritariamente correspondem a esse primeiro segmento. Como podemos observar nas respostas de P144 (Participante 144) curso de Engenharia de alimentos e P146 - curso de Engenharia de Alimentos.

“Alimento com micro-organismos vivos que combatem doenças" (P144 - curso de Engenharia de Alimentos)

"São alimentos que contêm micro-organismos vivos que auxiliam no equilíbrio da flora intestinal." (P146 - curso de Engenharia deAalimentos)

Esse segmento também é caracterizado pelos participantes conseguirem definir funções dos alimentos probióticos, as respostas dialogam com a definição feita por Puupponen-Pimiä et al. (2002) que define como função de alimentos probióticos “a estimulação da multiplicação de bactérias benéficas, em detrimento à proliferação de bactérias potencialmente prejudiciais, reforçando os mecanismos naturais de defesa do hospedeiro devido ao equilíbrio da flora intestinal", como pode-se observar nas respostas de P4 - curso de Engenharia de Alimentos , P26 - curso de Comunicação Social - Jornalismo e P57 - curso de Enfermagem

“Que ajuda no funcionamento do intestino” (P4 - curso de Engenharia de Alimentos)

"Um alimento que faz bem à saúde, ajudando com a digestão e a imunidade” (P26 - curso de Comunicação Social Jornalismo)

“Aquele que auxilia positivamente na manutenção da flora intestinal natural do indivíduo" (P57 - curso de Enfermagem) 
Como o perfil da amostra analisada se refere a estudantes que são em sua maioria da área da saúde e tecnologia, estimava-se que o percentual para definição clara do que seria um produto probiótico fosse expressiva, principalmente pelos estudantes de Engenharia de Alimentos, Enfermagem e Medicina, devido a ter objetos de estudos relacionados à promoção da saúde, alimentos funcionais e probióticos. A análise do segmento aponta que os Estudantes de Engenharia de Alimentos correspondem a 33\% desse segmento, os estudantes de enfermagem compõem 19,38\% desse segmento e medicina corresponde a 23,83\% da população que definiu probiótico dialogando com a legislação, a expressividade de definições corretas por parte dos participantes de produto funcional probiótico foram surpreendentemente positivas.

O segundo segmento, saudável e benéfico, conta com respostas dos participantes que fazem referência às informações mais gerais para definição de alimentos probióticos adjetivando o produto, ou seja, dando características inerentes ao produto. As respostas foram obtidas das diferentes áreas de ensino, havendo um equilíbrio entre o perfil de consumidor obtido, e foi o segundo segmento de maior expressividade de acordo com o comportamento da população amostral. Como podemos observar nas respostas de P158, P177 e P249.

\author{
"Benéfico ao ser humano" (P158 - curso de Medicina) \\ "Que faz bem à saúde" - (P177 - curso de Enfermagem) \\ "Que faz bem pra saúde" - (P249 - pós-graduação em Ciências dos Materiais)
}

Já o segmento, não sei, os participantes não souberam definir um alimento probiótico, funções ou adjetivos inerentes, correspondendo a menor expressão das respostas, tendo em sua maioria os estudantes das áreas de humanas devido as respostas pertencerem ao grupo de cursos: Direito, Comunicação Social - Jornalismo, Licenciatura em Ciências Humanas, Ciências Contábeis e Pedagogia. Como pode-se observar nas respostas de P250, P258, P312 e P317.

\author{
"Não sei" - (P250 - curso de Pedagogia) \\ "Não sei" - (P258 - curso de Direito) \\ "Não sei definir" (P312 - curso de Ciências Contábeis) \\ "não tenho ideia" (P317 - curso de Comunicação - Jornalismo)
}

Percebe-se que o perfil da amostra utilizada nesse estudo sabe a definição de um produto probiótico, e quando não consegue, recorrem primariamente aos adjetivos desses produtos, percebe-se também que com o avanço do tempo, novas tecnologias e produtos, há o crescimento da popularização desses produtos, o construto de Holanda (2008) identificou que apenas $8 \%$ da sua amostra de 198 participantes souberam a definição de produto probiótico, nota-se que o acesso à informação desse tipo de alimento aumentou consideravelmente, seja por indicação médica, nutricional ou por procura própria dos indivíduos para uma vida mais saudável ao observar os dados de Cruz (2016) na qual verificou-se que em uma amostra de 124 pessoas, $66 \%$ conseguiram definir probiótico corretamente, e para essa pesquisa a maior expressão de comportamento dos participantes foi definir corretamente o produto ou função. 
Em relação aos produtos probióticos que os participantes já consumiram, foram solicitados a assinalar os alimentos probióticos que consome, "Assinale os produtos que você já consumiu". Onde cada participante poderia selecionar mais de uma opção e cada um dos produtos recebiam uma numeração em que 1 se referia a Kefir, 2 a Kombucha, 3 a Leite Fermentado, 4 se referia ao não consumo, 5 à iogurtes, 6 refere-se a queijos e 8 comprimidos/suplementos alimentares probióticos, a análise é importante para entender com quais produtos probióticos o perfil social dessa população fez a inserção desse tipo de alimento em sua dieta e essa indicação numérica foi usada para os testes quantitativos.

Percebeu-se que o alimento probiótico que faz a inserção desses produtos na dieta da população analisada é o leite fermentado, tendo o apontamento de 49,18\% da população. As características do leite fermentado que fazem esse perfil ser adepto ao consumo desse produto podem ser inúmeras, como a acidez desejável do produto, a base de leite, o flavor característico, viscosidade, textura e outros aspectos sensoriais relevantes (Gallina, 2012), Os demais produtos tiveram uma taxa de resposta baixa comparado ao leite por parte dos entrevistados , Kefir, por exemplo, foi consumido por 12,5\% da população, 11,88\% consumiram vegetais fermentados, o consumo de Kombucha representa 11,47\%, 10,65\% da população não consome funcionais probióticos, 3,48\% indicaram o iogurte, e os demais produtos tiveram representatividade abaixo de 1\%. Filho (2020), também teve como principal alimento de inserção, produtos lácteos, porém os queijos foram principais produtos consumidos pela população seguido de iogurtes e leite fermentado.

Ao realizar a média com desvio padrão com a numeração descritas para os produtos probióticos mencionados anteriormente, obteve-se o resultado de $3,11 \pm 1,27$, o que significa que o perfil de consumidor do presente construto tem a inserção de probióticos pelo leite fermentado acidófilo tipo Yakultæ.

De acordo com o teste $t$ de Student não há semelhança ou associação entre os produtos indicados, eles são diferentes e o resultado se tem como significativo, em que p-valor de aproximadamente 0 é menor que margem de erro amostral de 5\% $(0,05)$, logo, somando com as análises anteriores e normalidade, o comportamento dessa população é ter a introdução de alimentos funcionais probióticos pelo leite fermentado, o que se percebe em outros construtos como 96\% da população de Holanda (2008)que também consome leite fermentado e iogurte.

Quanto a frequência de consumo dos alimentos probióticos, os resultados descreveram uma frequência de consumo bem distribuído entre as faixas colocadas, o maior percentual foi em relação a frequência semestral, com 29,05\% das respostas dos participantes, porém a faixa de consumo mensal e não consumo representam 22,93\% e 19,57\% respectivamente, o que se percebe é que quanto maior o espaço entre um consumo e outro, sendo o maior intervalo a faixa semestral, maior é a quantidade de respostas dos participantes correspondente a esse comportamento com exceção da faixa de não consumo.

As frequências de consumo receberam também receberam numerações em que 1 se referia a frequência diária de consumo, 2 a frequência de 2 a 3 vezes por semana, 3 se refere ao consumo quinzenal de produtos probióticos, 4 ao consumo mensal, 5 ao consumo semestral e 6 indica o não consumo dos participantes. A média das indicações é de 4,28 $\pm 1,29$. O tratamento dos dados estatísticos revela um comportamento de consumo de frequência média mensal-semestral, as faixas são distintas entre si, esse consumo semestral e mensal até o seguinte momento do trabalho deve-se ao próprio perfil da população que apesar da maioria pertencer à área da saúde e tecnologia não promove a saúde e adota um estilo de vida com hábitos saudáveis por ausência de doenças crônicas, esses valores são estatisticamente significativos e as faixas de frequência são distintas entre si de acordo com valor do teste $\mathrm{Z}$ já que $\mathrm{p}$-valor $\cong 0,000001$, sendo menor que o erro amostral de 0,05 estabelecido no seguinte construto, no estudo de Filho (2020), 37,90\% responderam ser de 3 a 4 vezes por semana, e ainda perguntado aos participantes que fazem o uso de probióticos para regular o intestino, se eles notaram as melhorias ao consumirem o produto, 36,60\% afirmaram que sim, corroborando com Bayer (2012) ao mencionar que os principais benefícios apontados pelos consumidores 
de alimentos probióticos é a melhora da função intestinal $(34,4 \%)$ e o fortalecimento do sistema imunológico (29,1\%), essa funções foram descritas pela população do seguinte estudo fazendo parte do segmento 1 das definições de alimentos probióticos.

A frequência do consumo de alimentos probióticos diz respeito a quantidade de uso desses produtos em um determinado espaço de tempo pela população analisada. A importância dessa análise se dá para a leitura da efetivação da inserção desses produtos na dieta em relação ao perfil determinado pela população incluída nesse estudo, pois por mais que o consumidor tenha feito indicação de produto, se ele apenas consumiu uma vez e não fez mais o uso, isso não se caracteriza como perfil de consumo de algum produto.

Em um estudo comparativo com a frequência de consumo com o produto consumido, referido como responsável pela inserção de probióticos na dieta da amostra, os maiores percentuais analisados na associação demostraram que $25 \%$ da população consome leite fermentado acidófilo na frequência semestral, 20,7\% consomem o produto na frequência mensal, 15,6\% consomem na faixa quinzenal de consumo, 14,06\% não consomem probióticos de modo algum, Holanda (2008) teve 50\% da sua população indicando consumir iogurtes e leite fermentado mensalmente-semestralmente.

Em todas as faixas de frequência de consumo, o produto mais consumido primariamente pela população segue sendo o leite fermentado com exceção de quem não consume produtos probióticos, o perfil descrito até então após a análise integral desses dados são jovens estudantes de graduação de classe média baixa da área da saúde e tecnologia que possuem um estilo de vida sedentário mas não apresenta problemas de saúde e que consome leite fermentado como principal produto probiótico na frequência semestral.

Já se sabe que o principal produto de inserção desse tipo de alimento na dieta do perfil de população analisada é o leite fermentado, mas isso não corresponde necessariamente que isso seja o alimento probiótico favorito dessa amostra, a análise de um alimento favorito seja ele funcional probiótico ou não tem sua devida importância por que além dos atributos de um produto de inserção em dieta, no desenvolvimento de um produto é importante saber das propriedades que deixam o consumidor com memória afetiva positiva, tendo aquisição do produto de maneira hedonicamente por uma boa experiência.

Para esse teste foram colocados os seguintes produtos para escolha: Kefir, Iogurte, Kombucha, Tempeh, Queijos e Leite Fermentado. As escolhas dos entrevistados estão dispostas no Gráfico 2:

Gráfico 2: Produtos probióticos preferidos pela população.

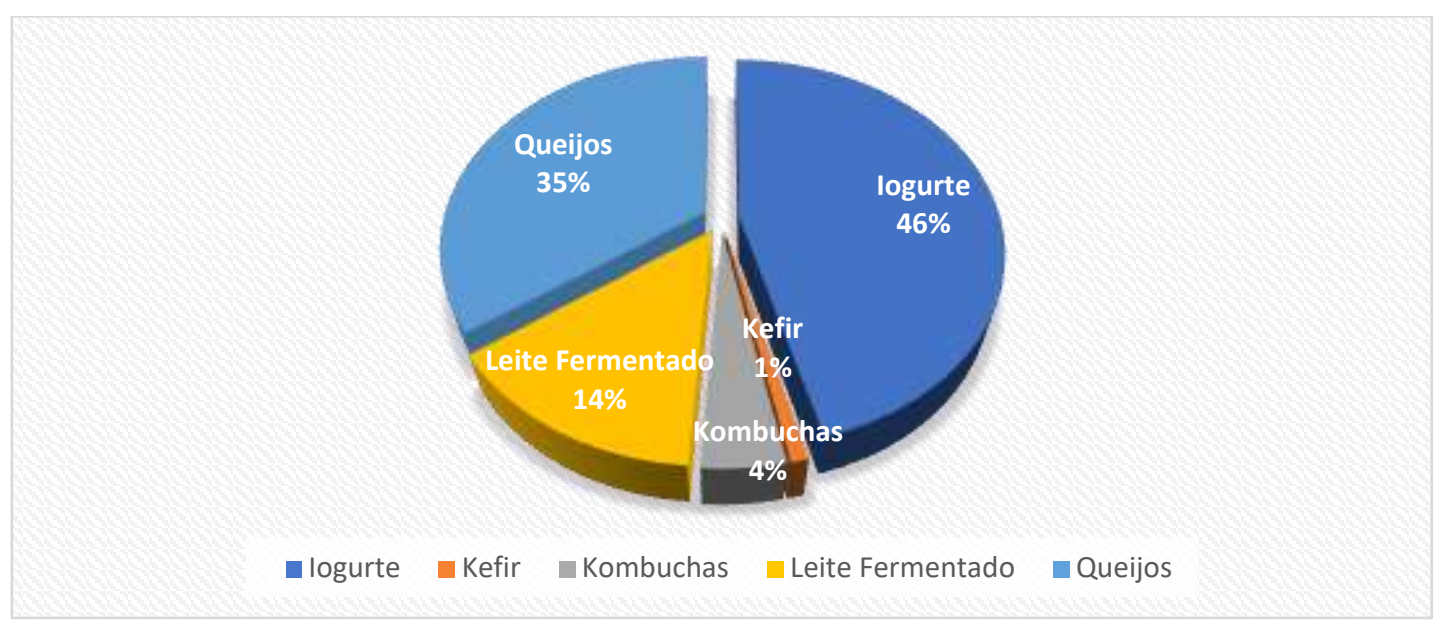

Fonte: Autores (2021). 
De acordo com os dados obtidos nesse teste, o leite fermentado atua como um bom produto de inserção aos alimentos probióticos, mas os probióticos que proporcionam afetividade do perfil da amostra do estudo são iogurtes e queijos probióticos de acordo com o Gráfico 2.

Os iogurtes são apontados como os produtos mais preferido pelos estudantes, isso deve corresponder ao seu relativo baixo custo, já que a o perfil de pessoas do estudo são de classe média-baixa, além dos fatores de variedade e fácil aceitação sensorial, o que foi apontado por Freeman (2020), que argumenta que o consumidor está em busca do melhor custo-benefício. Percebe-se que os produtos de inserção e que causam aderência de preferência são a base de leite, provenientes de fermentação lática, os iogurtes devem apresentar preferência hedônica devido a inclusão de saborização de frutas além do apelo em embalagens de promoção à saúde.

Em relação a indicação do motivo da preferência/consumo do seu alimento favorito por parte dos entrevistados, os produtos probióticos que foram descritos como preferido ou de inserção em dieta tinha-se apenas uma perspectiva do que levaria a escolha, ao analisar quais fatores são importantes para a aderência desses produtos tem-se os dados aparentes obtidos no Gráfico 3.

Gráfico 3: Fatores que acarretam a preferência de um produto dentro dos alimentos funcionais probióticos sem associações entre as variáveis feitas pelos participantes.

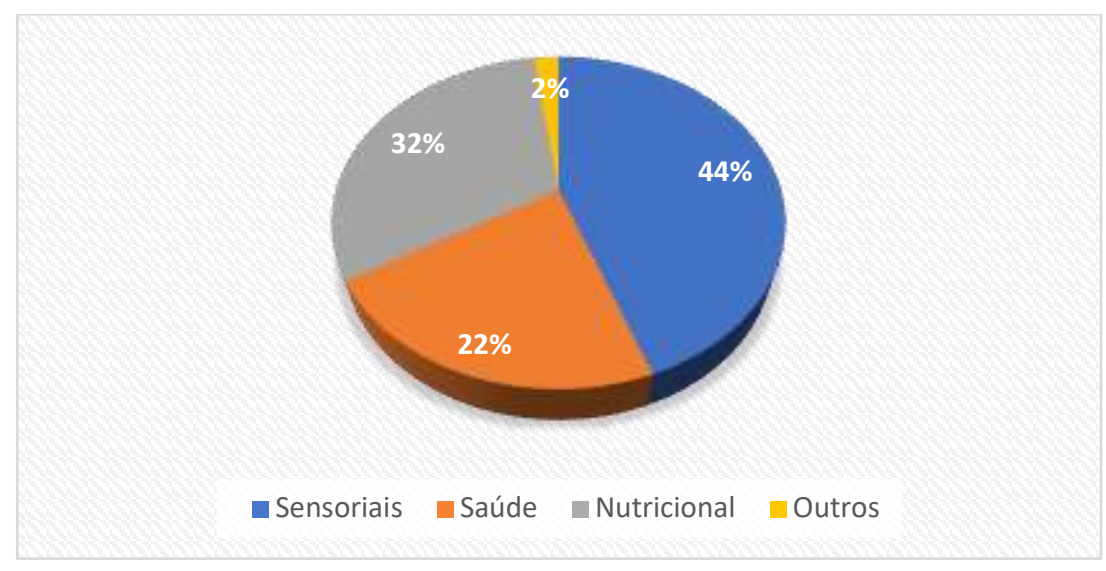

Fonte: Autores (2021).

Os entrevistados apontaram levar em consideração os fatores nutricionais, sensoriais e de saúde para a escolha de um alimento probiótico, mas se analisar-se apenas os fatores separadamente sem aglutinação o motivo da escolha se volta apenas para um fator bem definido.

O perfil de consumidor adquirido para a entrevista revela levar em consideração majoritariamente ao desagregar atributos, o fator sensorial para a escolha do produto probiótico com 44,44\% de frequência relativa, o que é coerente já que o perfil se trata de jovens que são caracterizados estatisticamente como sedentários e por não ter problemas de saúde não amplia a dieta para produtos funcionais, apenas $22,07 \%$ da população prefere um probiótico por causa de motivos ligados à saúde, quando há a inclusão desses produtos a sensorial deve conquistar o consumidor para que haja a aderência, mas sem deixar os demais atributos de lado, afinal 31,48 \% dos entrevistados levam em consideração o fator nutricional.

Para levar em consideração o atributo sensorial que é um fator de grande expressão para a aderência de um alimento pelo perfil de consumidor obtido, foi perguntado aos participantes quais atributos sensoriais são levados em maior consideração para o consumo de alimentos probióticos, os atributos sensoriais expostos foram Aparência, Cor, Sabor, Aroma, Doçura, 
Sensação na boca, Teor Alcoólico e outros. Ao assinalar opções aglutinadas, os atributos mais relevantes para esse perfil de população com 8,56\% das respostas foram Aparência, Aroma, Cor e Sabor. Geralmente os produtos probióticos fermentados possuem um aroma característico própria do processo fermentativo e logicamente influi na escolha de um produto. Ao desagregar os atributos, as maiores frequências para os atributos foram 25,17\% sabor, 19,45\% Aroma e 16,89\% Aparência. Percebe-se que o sabor como atributo sensorial tem um peso bastante significativo na escolha desses produtos, sendo assim os probióticos que terão aderência por parte dessa população são produtos em que a biotecnologia traga uma experiência afetiva agradável, em que os produtos da fermentação não interfiram negativamente no sabor

\section{Do conhecimento e consumo de Kefir}

Ao avaliar o conhecimento de consumo do perfil de consumidor, revela-se que mais da metade da população analisada, nunca ouviu e nunca consumiu o Kefir, com 53,21\%, 27,52\% sabem do que trata a bebida, mas nunca consumiu, uma parcela bem pequena, 1,23\% consumiram sem saber e apenas 17,43\% da população sabe de fato o que é a bebida Kefir e consumiu.

A análise se torna coerente com os testes quantitativos anteriores, já que em relação aos produtos preferidos os valores são bem ínfimos, chegando a ser representado por 3 aderências em frequência absoluta, e em relação a produtos já consumido pela população apesar de ter um número expressivo pela população, o leite fermentado segue sendo referência aparente e estatisticamente. Tal desconhecimento para o Kefir se vem juntamente com a Kombucha devido serem produtos considerados novos de mercado e não estarem representativamente diversos e presentes no mercado, apesar de serem antigos, e a sensorial e sabor que é levado bastante em consideração pelo perfil do estudo deve interferir na adesão do Kefir.

As respostas "nunca ouvi e nunca consumi"(1), "consumi sem ouvir falar"(2), "sei do que se trata e não consumi”(3) e "sei do que se trata e já consumi"(4) não mostraram equilíbrio, a população apresenta não homogeneidade em suas respostas, não apresentando diversidade igualitária entre as classes divididas na análise sobre o conhecimento e consumo de Kefir, isso significa que para o Kefir a amostra segue predominantemente algum comportamento ou característico, que pelo resultado de frequências é não conhecer e nem consumir o Kefir.

A aderência de consumo e conhecimento de Kefir, compara o grau de concordância entre as distribuições acumuladas

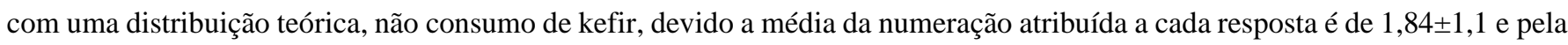
normalidade analisada, pelo teste de Lilliefors rejeita-se a hipótese de nulidade de que as respostas dos participantes não se diferem da distribuição esperada "nunca ouvi e nunca consumi" (4), havendo diferença significativa e como p-valor unilateral e bilateral é menor que 0,01 e o erro amostral padrão é de 0,05 , a população pode ter comportamento de não conhecer e consumir o kefir mas não adere essa normalidade, sendo assim outras respostas também atrelam comportamento aos indivíduos.

Assim como esse construto, Santos et al (2012), ao relatar uma análise sensorial de kefir de manga, além de perceber que o produto teve uma aceitação bastante satisfatória, demonstrando a viabilidade de sua produção, principalmente pelo valor nutricional e funcional, durante a realização da análise sensorial, observou-se que pouquíssimos provadores conheciam o kefir. Resultados semelhantes foram observados por Santos et al. (2011) quando realizaram o teste de aceitação com o kefir sabor natural na mesma região, logo, a população amostral analisada pode não conhecer o Kefir, mas pode aceitar um Kefir a base de albedo de maracujá, cuja prospecção de mercado também será alvo desse estudo.

Ao avaliar a diversidade de Kefir no mercado, foram atribuídas numerações de 1 a 5, em que 1 representa pouquíssimo diverso, 2 pouco diverso, 3 diversos, 4 muito diverso. Analisando se o baixo conhecimento do produto é devido o produto realmente não ter expressão na competitividade de mercado dentre as demais opções em uma escolha de consumo, essa expressão é marcada como a variedade de Kefir, ou alimentos à base de Kefir dentro do potencial de compra. A análise 
apontou que $48 \%$ dos entrevistados definiram como pouquíssimo diverso a variedade de kefir no mercado, 44,3\% definiram como pouco diverso, $7,3 \%$ definiram como muito diverso e $0,3 \%$ como muitíssimo diverso

Nota-se que o produto Kefir é comercialmente desconhecido pela população analisada devido a sua ausência de variedade no mercado, apesar de consumirem produtos probióticos, principalmente à base de leite, esse desconhecimento descrito no teste anterior aparece quando o produ to é pouco expressivo nas prateleiras de exposição para consumo aliado com a falta de promoção a saúde do perfil da amostra analisada.

Estatisticamente, a média das numerações que indicam a variedade de produtos (1-4) é de 1,59 $\pm 0,40$, foi visto que a indicação 1 se refere a pouquíssimo diverso e 2 pouco diverso, sendo assim; o tratamento estatístico leva que o resultado do teste indica que a variedade de Kefir é pouquíssima diversa segundo a população entrevistada, ou seja, no mercado, o produto não tem expressividade em prateleiras. Em um teste Z, o valor de força (p) unilateral de 0,33 é maior que o erro amostral estabelecido no cálculo de tamanho da amostra $(0,05)$, sendo assim, o teste $\mathrm{Z}$ indica que a média de 1,59 representa a varie dade de Kefir no mercado.

Além da pouca variedade de mercado, outros fatos que corroboram para que o Kefir não tenha uma taxa crescente de consumo exponencial, ao fazer a análise desses demais fatores, dando a opção de aglutinar fatores para a demonstração de respostas dos entrevistados obteve-se que mesmo sem desagregar os fatores, já é bem nítido que a população analisada não consegue opinar sobre o que limita esse consumo, como a população não sabe opinar sobre esses fatores, só se identifica ainda mais a amostra estudada como desconhecedora do produto Kefir, e esse desconhecer faz com que seu consumo seja realmente baixo.

Além dos participantes não terem o poder de opinião por desconhecer o produto Kefir que representa 37,77\% , os aspectos sensoriais, com 21,07\% das respostas da população analisada, é o primeiro fator que limita esse consumo, viu-se anteriormente que esse é o principal aspecto de aderência afetiva de um produto por parte da população analisada principalmente o sabor, esses fatores aliados com a falta de variedade de Kefires tornam a expansão do consumo para a população analisada difícil, outros aspectos como disponibilidade, preço e preferência por bebidas alcóolicas representam $19,37 \%, 12,59 \%$ e $9,2 \%$ respectivamente .

\section{Intenção de consumo e compra de um novo produto a base de kefir e albedo de maracujá (Passifora edulis).}

Previamente a aceitação do produto maracujá pelo perfil analisado é importante para a prospecção de mercado para um produto a base do albedo de maracujá. Antes de saber exatamente sobre o mesocarpo do maracujá, é necessário ver a aceitação do fruto maracujá para inclusão na formulação de um novo produto, hedonicamente o produto tem uma aceitação alta por parte dos entrevistados, foram feitas indicações em que 1 se refere a desgostar e 9 gostar muitíssimo, com mais da metade das indicações, o gostar muitíssimo representa 59,33\% nessa análise, e 28,44\% é a indicação para gostar moderadamente. Vê-se uma aceitação majoritária do fruto, demostrando um apreço por parte do perfil analisado, como já se sabe que o fruto maracujá é bem aceito, passa-se às informações inerentes ao albedo ou mesocarpo desse fruto que é o foco de um protótipo de elaboração de um novo produto.

Em relação ao conhecimento sobre a utilização do albedo do maracujá na formulação e desenvolvimento de produtos alimentícios .O estudo já aponta que o perfil descrito na pesquisa sabe definir um produto funcional probiótico, mas não tem o hábito de consumir produtos probióticos novos como Kefir e isso também se expande para o conhecimento do albedo do maracujá como parte da formulação de alguns alimentos benéficos a saúde já que $74 \%$ da população desconhece totalmente o componente do fruto do maracujá, em seguida $18,34 \%$ conhecem o albedo mas nunca consumiu nada com esse componente na formulação, apenas 7,64\% sabem do que se trata e consumiram. A diferença entre as proporções é significativa em um 
teste bilateral e verificando que a força de valor-p para 0,05 de erro é bem menos que o p-valor encontrado $(<0,0000001)$, aceita-se a hipótese que a população desconhece o albedo do maracujá.

Em relação a aderência da população para esse novo produto, de acordo com a leitura da análise aparente e estatística pode se saber a intenção de compra do mercado do perfil de população analisado no estudo se esse Kefir existisse, obteve-se que $57,4 \%$ da população compraria, $32,41 \%$ consumiriam, mas não compraria o produto e 10,09\% não consumiria e nem compraria o produto, Moura (2019), fez testes sensoriais para um antepasto a base de kefir de albedo de maracujá, houve uma aceitação sensorial satisfatória dos produtos, sendo que a formulação controle apresentou melhor aceitação do que as formulações adicionada de farinha de albedo de maracujá. Por ser um produto de baixo custo, alto valor nutricional e de fácil acesso pela população, faz-se necessário realizar outras pesquisas com kefir, especificamente sobre seu comportamento no trato digestivo humano.

Nota-se que a população amostral, apesar de não conhecer o Kefir, as limitações de consumo e nem terem um estilo de vida que favoreçam a promoção da saúde, eles consumiriam e comprariam o produto formulado com albedo de maracujá, tendo um potencial de mercado e de inserção, com a agregação dos fatores que despertem os interesses de aderência afetiva, a população desse estudo pode inserir o produto em sua dieta, seguindo uma tendência mundial que é o aumento das bebidas probióticas na vida de um consumidor.

Pelos resultados do teste de aderência de Lilliefors, há diferença significativa entre os comportamentos de aderência pelo resultado do teste verifica-se que estatisticamente mesmo a população apontando a intenção de compra de Kefir a base de albedo do maracujá, de acordo com o p-valor $(<0,01)$ em relação ao erro amostral do presente trabalho de 5\%, a população não adere a normalidade que é a compra e consumo de Kefir, havendo comportamentos significativos de intenção de não consumo e compra inerentes ao perfil.

Esse comportamento de não consumo e não compra demostrado por 10,09\% da população foi analisado em 4 segmentos através da justificativa dos participantes, $28,59 \%$ justificaram o não consumo devido a particularmente não ter nenhuma aderência afetiva pelo Kefir em experiências obtidas com o consumo ou ainda preferir outros tipos de produto em detrimento do kefir. O segundo segmento é formado por pessoas que levam em consideração/relevância a presença da experiência sensorial para efetivação do consumo, sendo 38,23\% da população que não consumiria o produto, o terceiro segmento formado por $11,79 \%$ é composto por pessoas com incompatibilidade particular com o maracujá e seus derivados, e o último segmento é composto por pessoas que por desconhecer totalmente o produto Kefir e o albedo de maracujá, não consumiria o produto, representando 29,41\% desse nicho.

Assim como o construto, a pesquisa realizada por Moura (2019) e Bayarri et al. (2011), verifica-se que os produtos lácteos fermentados costumam ter elevada aceitação sensorial, mas a maioria dos consumidores preferem formulações com menor grau de acidez. Porém, mesmo formulações apresentando elevada acidez, a aceitação pode ser satisfatória, o que reforça o afirmado por O'Brien et al. (2017) de que, além dos consumidores que desaprovam os produtos ácidos, existem muitos outros que desfrutam da acentuada acidez e perfil de sabor complexo associado ao kefir tradicional., corroborando ainda com o estudo realizado por Rocha et al. (2014), onde os autores avaliaram um 'labneh"' produzido com kefir, e o produto apresentou boa aceitação para os atributos aparência, sabor, textura e impressão global.

O perfil de consumidor desse estudo que não consumiria o produto se ele existisse devido à ausência de experiências sensoriais, por não saber qual o sabor do Kefir e se esse sabor seria uma experiência agradável ou não, mesmo o produto elevando o estilo de vida saudável dessas pessoas, o grande receio dos atributos sensoriais faz com que não somente o Kefir tenha fatores de impedimento de consumo, mas assim segue também com outros probióticos como Kombuchas e Tempeh, aumentar a popularização e o conhecimento da bebida seria logicamente aumentar o potencial do produto também, Kefir não é um produto 
alcóolico, a produção de etanol nesse probiótico é muito ínfimo, não podendo ser caracterizado dessa forma e teve uma certa frequência de pessoas que tiveram essa impressão do produto por ele ser fermentado, juntando os demais fatores de desconhecimento da bebida, o produto perde a sua força de mercado, todos os fatores obtidos nessa análise devem ser trabalhados para que futuramente num projeto que envolva o desenvolvimento dessa bebida, os requisitos apontado por esse tipo de consumidor seja atendido.

\section{Conclusão}

A população participante da pesquisa corresponde à estudantes majoritariamente de graduação e pós-graduação da área da saúde e tecnologias em sua maioria, pertencentes a faixa de 24 anos, homens ou mulheres que se encaixam na classe médiabaixa de poder aquisitivo familiar, essa população possui um estilo de vida sedentário e não apresentam problemas de saúde. O perfil descrito sabe definir um produto probiótico, e tem como produto de inserção desses produtos na sua vida o leite fermentado, e como preferência afetiva escolhem os iogurtes como probióticos em sua dieta alimentar, apesar de terem produtos de preferência e inserção, o perfil de consumidor analisado tem hábito de consumo de produtos probióticos mensal-semestral devido à influência dos atributos sensoriais principalmente o sabor. O perfil não tem conhecimento sobre Kefir e produtos formulados com albedo do maracujá e quase em sua totalidade não consumiram por não conhecer os produtos e por falta de experiências sensoriais, mesmo com esses entraves sobre o Kefir e albedo do maracujá, o perfil mostrou interesse de consumo em um Kefir elaborado a base de albedo de maracujá, sendo necessário na existência de estudos futuros de desenvolvimento da bebida o atendimento para popularização da bebida e de mudança de hábitos do perfil estudado para crescimento de vida ativa e requisitos para compor boas experiências sensoriais do produto em questão para que haja aderência do produto e seguir a tendência mundial de consumo desses produtos.

\section{Agradecimentos}

À Universidade Federal do Maranhão pelo suporte e pela disponibilização de meios para a realização da pesquisa.

\section{Referências}

Artilha, C. A. F., Da Silva, D. D. M. B., Alves, E., De Sousa, L. C. S., Saqueti, B. H. F., Stafussa, A. P. \& Madrona, G. S. (2020). Leites fermentados uma revisão/Fermented milk-a review. Brazilian Journal of Development, 6, 1, 4956- 4968.

Balthazar, C. F., Pimentel, T. C., Ferrão, L. L., Almada, C. N., Ssantillo, A., Alabenzio, M., Mollakhalili, N., Mortazavian, A. M., Nascimento, J. S., Silva, M. C., Freitas, M. Q., Sant'ana, A. S., Granato, D., \& Cruz, A. G. (2017). Sheep Milk: Physicochemical Characteristics and Relevance for Functional Food Development. Comprehensive. Reviews in food science and food safety, v. 16, p. 247-262.

Bayarri, S., Carbonell, I., Barrios, E. X., Costell, E. (2011). Impact of sensory differences on consumer acceptability of yoghurt and yoghurt-like products. International Dairy Journal, 21, 111-118.

Bayer, K. H. (2012). Levantamento do nível de conhecimento dos consumidores sobre os alimentos funcionais no município de Ponta Grossa (PR). Orientador: Ms. Eliana Queiroz Bortolozo, 2012, 60f. Trabalho de Conclusão de Curso (Tecnologia em Alimentos) - Universidade Tecnológica Federal do Paraná, Ponta Grossa.

Bardin, L. (2011). Análise de conteúdo: Edições 70, 229 p.

Bloch, K. V., \& Coutinho, E. S. F. (2009). Fundamentos da Pesquisa Epidemiológica. In: Medronho, R. A., et al. Epidemiologia. Editora Atheneu, p173-179

Brasil. Agência Nacional de Vigilância Sanitária, ANVISA. (2018). Resolução n. 241, de 26 de julho de 2018. Requisitos para comprovação da segurança e dos benefícios à saúde dos probióticos para uso em alimentos.

Bornia, A. C., Barbetta, P. A., \& Reis, M. M. (2009). Estatística para Cursos de Engenharia e Informática. (2a ed.), Atlas.

Cruz, G. F. R. (2016). O comportamento do consumidor de alimentos funcionais. Orientadora: Dra. Marlette Cassia Oliveira Ferreira. 2016. 88f. Trabalho de Conclusão de Curso (Tecnologia em Processos Gerenciais) - Instituto Federal de São Paulo, Caraguatatuba.

Filbido, G. S., Siquieri, J. P. A. \& Bacarji, A. G. (2019). Perfil do consumidor de alimentos lácteos funcionais em Cuiabá-MT. Revista Principia, 45, 1,31-39. 
Filho, W. F. S. B, Torres, L. N., Barros, M. C. L. B., \& Sousa, S. F. (2020). Alimentos funcionais probióticos, um novo estilo de vida. Congresso Internacional da Agroindústria - CIAGRO 2020,

Furtado, L. L. (2017). Viabilidade de bactérias probióticas em suco tropical de manga e sobrevivência das estirpes às condições gastrointestinais simuladas in vitro. 2017, 48f. Dissertação (Mestrado Profissional em Ciência e Tecnologia de Alimentos) - Instituto Federal de Educação, Ciência e Tecnologia do Sudeste de Minas Gerais- Campus Rio Pomba.

Gallina, D. A., Alves, A. T. S., Trento, F. K. H. S. \& Caruzi, J. (2015). Caracterização de leites fermentados com e sem adição de probióticos e prebióticos e avaliação da viabilidade de bactérias láticas e probióticas durante a vida-deprateleira. Journal of health sciences, 13, 4, 239-244.

Gallina, D. A. et al. (2012). Caracterização de bebida obtida a partir de leite fermentado simbiótico adicionado de polpa de goiaba e avaliação de viabilidade das bifidobactérias. Revista do Instituto de Laticínios Cândido Tostes, Juiz de Fora, 67, 45-54.

Holanda, L.V, Antunes, A. L, Del Santo, R, \& Muniz, V. O. (2008). Conhecimento sobre probióticos entre estudantes de uma Instituição de Ensino Superior. INTELLECTUS - Revista Acadêmica Digital do Grupo POLIS Educacional.

Jeong, D., Kim, D.H., Kang, II. B., Kim, H., Song, K.Y., Kim, H. S., \& Seo, K. H. (2017). Characterization and antibacterial activity of a novel exopolysaccharide produced by Lactobacillus kefiranofaciens DN1 isolated from kefir. Food control, 78, 436- 442.

Kim, J. Y., Lee, S. Y., Jung, S. H., Kim, M. R., Choi, I. D., Lee, J. L., Sim, J. H., Pan, C. H., \& Kang, K. (2020). Protective effect of Lactobacillus casei HY2782 against particulate matter toxicity in human intestinal CCD-18Co cells and Caenorhabditis elegans. Biotechnology Letters, 42(4), 519-528. http://dx.doi.org/10.1007/s10529-020-02814-3

Kleerebezem, M., Binda, S., Bron, P. A., Gross, G., Hill, C., van Hylckama Vlieg, J. E., Lebeer, S., Satokari, R., \& Ouwehand, A. C. (2019). Understanding mode of action can drive the translational pipeline towards more reliable health benefits for probiotics. Current Opinion in Biotechnology, 56, 55-60. http://dx.doi.org/10.1016/j.copbio.2018.09.007

Manarini, T. (2018) Os benefícios do kefir, sob o olhar da ciência. https://saude.abril.com.br/alimentacao/os-beneficios-do-kefir-sob-o-olhar-da-ciencia/.

Moura, A. C. T. (2019). Desenvolvimento de antepasto de kefir enriquecido com Lactobacillus acidophilus La-5 e coprodutos industriais. Trabalho de Conclusão de Curso (Pós-graduação Stritu sensu em Ciência e Tecnologia em Alimentos) - Instituto Federal de Educação, Ciência e Tecnologia do Sudeste de Minas Gerais - Campus Rio Pomba.

O`Brien, K. V., Lisano, J., Shackelford, D., Reeves, K., Christensen, M., Hayward, R. Prinyawiwatkul, W., Cabarante Ordonez, K. M., \& Boekene, C. A. (2017). Short communication: Sensory analysis of a kefir product designed for active cancer survivors, Journal of Dairy Science, 100, 4349-4353

Otle, S., Cagindi, O. (2003). Kefir: a probiotic dairy-composition nutritional and therapeutic aspects. Pakistan Journal of Nutrition, 2 , . 54-59.

Puupponen-Pimia, R., Aura, A. M., Oksman-Caldentey, K. M., Myllarinen, P., Saarella, M., Matilla-Sanholm, T., \& Poutanen, K. (2002). Development of functional

ingredients for gut health. Trends Food Sci. Technol., Amsterdam, 13, 3-11.

Rocha, D. M. U. P., Martins, J. de F. L., Santos, T. S. S., \& Moreira, A. V. B. Labneh with probiotic properties produced from kefir: development and sensory evaluation. Food Science and Technology, 34, 694-700, 2014.

Santos, F. L., Pereira, F. S., \& Sousa, A. C. (2011). Avaliação da aceitação de kefir natural produzido com leite de vaca. In: Congresso Latino Americano De Analistas De Alimentos, 3., 2011, Cuiabá. Anais eletrônicos. Cuiabá: UFMT. 1 CD-ROM

Santos, Ferlando \& Silva, Edleuza \& Barbosa, Adna \& Silva, Joseane. (2012). Kefir: uma nova fonte alimentar funcional? Diálogos \& Ciência. 10. 1-14. $10.7447 / \mathrm{dc} .2012 .001$

Silva, P. V. C., \& Costa Jr, A. L. (2011). Efeitos da atividade física para a saúde de crianças e adolescentes. Psicologia Argumento, 29(64): 41-50 https://periodicos.pucpr.br/index.php/psicologiaargumento/article/view/19915/19213

Silva, V, S., \& Orlandelli, R. C. (2019). Desenvolvimento de alimentos funcionais nos últimos anos: uma revisão, Revista Uningá, 56, 182-194

Vieira, S., \& Hossne, W. S. (2015). Metodologia científica para a área da Saúde. (2nd ed.), Elsevier.

Weschenfelder, S. (2011). Caracterização físico-química e sensorial de kefir tradicional e derivados. Arq. Bras. Med. Vet. Zootec., 63, .473-480.

Witthuhn, R. C., Schoeman, T., Cilliers, A., \& Britz, T. J. (2004).Impact of preservation and different packaging conditions on the microbial community and activity of kefir grains. Food Microbiology, 22, 337-344.

Yahfoufi, N., Mallet, J. F., Grahan, E., \& Matar, C. (2018).Role of Probiotics and Prebiotics in Immunomodulation. Current Opinion. Food Science, 20, 8291 .

Zhou, Z., Chen, X., Sheng, H., Shen, X., Sun, X., Yan, Y., Wang, J., \& Yuan, Q. (2020). Engineering probiotics as living diagnostics and therapeutics for improving human health. Microbial Cell Factories, 19(1), 56http://dx.doi.org/10.1186/s12934-020-01318-Z 